Dokuz Eylül Üniversitesi-Mühendislik Fakültesi

Fen ve Mühendislik Dergisi

Cilt 19, Sayı 56, Mayıs 2017
Dokuz Eylul University-Faculty of Engineering Journal of Science and Engineering Volume 19, Issue 56, May 2017

DOI: $10.21205 /$ deufmd. 2017195650

\title{
Kayaçların Equotip Sertlik İndeksi ile Mekanik Özellikleri ve Delinebilirliği Arasındaki İlişkiler
}

\author{
Okan SU*1, Moe MOMAYEZ2
}

${ }^{1}$ Bülent Ecevit Üniversitesi, Madencilik ve Maden Çıkarma Bölümü, 67500, Zonguldak ${ }^{2}$ Arizona Üniversitesi, Maden ve Jeoloji Mühendisliği Bölümü, 85721, Tucson, AZ, USA

(Alınıș / Received: 10.12.2016, Kabul / Accepted: 17.02.2017, Online Yayınlanma / Published Online: 02.05.2017)

Anahtar Kelimeler Özet: Yeraltı maden galerileri veya tünel kazısı sırasında uygun EquotipSertlik delici makine ve uç seçimi, makine performansını ve birim İndeksi, Delme Oranı İndeksi, Delinebilirlik, Jumbo Delici maliyetleri etkileyen önemli faktörlerdir. $\mathrm{Bu}$ seçim kayacın delinebilirlik, sertlik ve diğer mekanik özelliklerinin doğru olarak ölçülmesiyle yapılabilir. Bu makalede, öncelikle yurt içi ve yurt dışından alınan blok numuneler ISRM standartlarına göre uygun boyutlarda hazırlanmıştır. Daha sonra, laboratuvarda Equotip ve Shore sertliği ile mekanik özellikleri belirlenmiştir. Ayrıca, her bir numunenin delinebilirliğini sınıflandırmak üzere delme oranı indeksi ölçülmüştür. Bu bağlamda Equotip sertlik indeksi ile Shore indeksi, mekanik özellikleri ve delme oranı indeksi arasındaki ilișkiler incelenmiștir. Basit regresyon analizlerinden dayanımı 19 MPa'ın üzerinde ve delme oranı indeksi 70'in altında olan kayaçlarda Equotip sertlik indeksinin delinebilirliğin tahmininde güvenilir olarak kullanılabileceği belirlenmiştir.

\section{Correlation Between Equotip Hardness Index, Mechanical Properties and Drillability of Rocks}

Keywords

Equotip Hardness

Index,

Drilling Rate

Index,

Drillability,

Jumbo drill
Abstract: Selection of a jumbo drill and appropriate bit type are important factors affecting machine performance and unit costs when excavating a mine roadway or tunnel. The selection process can be optimized if the drillability, hardness and other mechanical properties of rocks are accurately measured. In this article, block samples collected at various locations around the world were initially prepared according to ISRM standards. Next, the Equotip hardness, Shore hardness, and mechanical properties were determined. In addition, the drilling rate index of the samples was measured and each sample was categorized based on its drillability. The relationship between Equotip hardness index, Shore index, drilling rate index, and other mechanical properties were analyzed. Simple regression statistics revealed that Equotip hardness index test could be reliably used to predict the drillability of rocks that have a compressive strength higher than $19 \mathrm{MPa}$ and a drilling rate index lower than 70 . 


\section{Giriş}

Madencilik çalışmaları kapsamında yeraltında cevhere ulașmak için farklı kesitlerde tabanyolu ve galeriler, tașıma amaçlı metro tünelleri; yeryüzünde ise karayolu, demiryolu, derivasyon vb. amaçlı tüneller açılmaktadır. Üretime veya faaliyete bir an önce geçebilmek için bu tünellerin en kısa zamanda, güvenli, ekonomik ve hızlı bir şekilde açılması hedeflenir. Ancak, kayaç yapısı, jeolojik ve hidrojeolojik koșullar ilerleme hızlarını etkiler. Bunun yanı sıra üretim yönteminin (klasik veya mekanize) de etkisi oldukça fazladır. Mekanize sistemlerle kazı yapıldığında genellikle üretim hızı ve miktarı artmakta, ancak ilk yatırım maliyetleri de yükselmektedir. Klasik delme-patlatma yönteminde ise maliyetler çok yüksek olmamakla birlikte ilerleme hızları nispeten daha düşüktür. Bunun nedeni, kazının kesintili devam etmesindendir. Yüksek üretim miktarlarına ulaşmak ve duraylı tünellerin açılmasını sağlamak için mekanize kazı sistemlerinden faydalanmak oldukça yararlı olmaktadır.

Mekanize sistemlerin uygulandığı koșullarda makinelerden yararlanılır. Bu sistemlerin tahkimat mekanizmaları genellikle ayna geometrisine ve jeolojik koşullara göre değişir. Kazı sistemleri (kesici kafa) ise tüm makinalarda farklılık gösterir. Klasik delme-patlatma yönteminde ise en önemli donanım delik delmede kullanılan makinedir. $\mathrm{Bu}$ bağlamda uygulandığı yere ve kesite göre martoperferatör veya jumbo delik deliciler yaygın olarak kullanılan makinelerdendir. Genellikle B14 ve üzerindeki kesitlerde jumbo deliciler uygulanabilmektedir. Kesit arttıkça 2 ve 3 kollu makineler de kullanılır. $\mathrm{Bu}$ makinelerin ilerleme hızlarının tayin edilmesi için öncelikle kayacın delinebilirlik özellikleri, ayrıca mekanik ve petrografik özelliklerinin belirlenmesi gerekir. Bu amaçla yaygın olarak yapılan deneylerden bir tanesi kayacın sertlik özelliklerinin belirlenmesidir. Sertlik, dıştan gelen bir mekanik etkiye karşı kayacın göstermiș olduğu dirençtir. Kaya yüzeyi üzerinde belirli bir baskı altında ucun ardışık olarak sıçraması ve geri sıçrama yüksekliğinin ölçülmesi ile sertlik belirlenir. Sıçrama yüksekliği kaya yüzeyinin elastik özelliği hakkında da bilgi verir [1]. Yani, sertlik hem kayacın delinebilirliğinin ve hem de dayanımının tahmin edilmesinde kullanılabilen bir indeks özelliğidir.

Sertliğin ölçülmesi kayaçlar için her ne kadar zor olsa da halen uygulanan üç yöntem bulunmaktadır. Bunlar batma deneyleri (Brinell, Rockwell C, Vickers, Knoop), dinamik veya geri ziplama sertlik deneyleri (Shore, Schmidt) ile çizme sertlik deneyleri (Mohs) dir [2,3]. $\mathrm{Bu}$ deneyler içerisinde geri zıplama sertlik deneyleri olan Shore ve Schmidt, madencilik ve inşaat endüstrisinde yaygin olarak uygulanmaktadır. Ancak, Shore sertlik indeksi deney aletinin günümüzde üretiminin oldukça azalması araștırmacı ve mühendisleri yeni deney aletlerinin geliştirilmesine sevk etmektedir. $\mathrm{Bu}$ amaçla uygulaması yaygınlaşan deney yöntemlerinden birisi Equotip sertlik indeksidir. Bu deney her ne kadar metallerin sertlik tayininde kullanılsa da artık günümüzde kayaçların yüzey sertliğini ölçmek üzere de uygulanmaya başlanmıştır. Equotip sertlik ölçerin çalıșma mekanizmasının Shore skeloroskobuna benzemesi, deneyin kayaçlar üzerinde uygulanabilirliğini daha da geçerli kılmaktadır.

\subsection{Shore sertlik indeksi}

Shore sertlik indeksi kayaçların sertliklerinin tahmin edilmesinde uygulanan oldukça basit ve ucuz bir deney yöntemidir. Deney; ilk olarak metallerin sertliğini belirlemek amaciyla 1907 yılında Albert F. Shore tarafından Amerika'da dizayn edilmiş olan Shore skeloroskobu ile yürütülmüştür. 1930'lu 
O. Su \& M. Momayez/ Kayaçların Equotip Sertlik İndeksi ile Mekanik Özellikleri ve Delinebilirliği Arasındaki İlişkiler

yıllarda ise skeloroskop kayaçların sertliklerinin belirlenmesinde kullanılmaya başlanmıștır [4]. Shore skeloroskopları C ve D model olmak üzere iki çeşittir. $C$ modelde $5,94 \mathrm{~mm}$ çap ve 2,3 gr ağırlığında uç kullanılırken, D modelde ise $7,94 \mathrm{~mm}$ çapında ve $36 \mathrm{gr}$ ağırlı̆̆ında elmas uç kullanılır [5]. D model Brinell ve Rockwell sertlik indekslerini de ölçebilmektedir.

Shore sertlik deney aletinde elmas veya tungsten karpitten üretilmiş bir ucun düzeltilmiş bir yüzey üzerine belirli bir yükseklikten serbest olarak düşürülmesi ve daha sonra ucun geri sıçrama yüksekliğine kayacın sertliği belirlenir. ISRM [2]'e göre deneyin uygulanması için en az $1 \mathrm{~cm}$ kalınlığındaki örneklerin minimum $10 \mathrm{~cm}^{2}$ lik parlatılmış yüzey alanına sahip olması gerekmektedir. Altındağ ve Güney [6] ise numune hacminin en az $80 \mathrm{~cm}^{3}$ olması gerektiğini önermiştir. ASTM [7]'e göre en az 15 mm kalınlıkla olmak şartı ile NX veya daha büyük boyutlarındaki karot numuneleri de deney için kullanılabilmektedir. Ayrıca, numuneleri sıcaklık değerlerinin sonuçları etkileyebileceği ve bu nedenle hepsinin aynı sıcaklık değerlerinde olması gerektiği önerilmektedir. Çünkü $0^{\circ} \mathrm{C}$ ve daha düşük sıcaklıktaki kayaçların çok yüksek geri sıçrama değerleri sergileyeceği belirtilmektedir [7].

Shore skeloroskobuna yerleștirilen örnek üzerinde en az $5 \mathrm{~mm}$ aralıklarla 20 okuma yapılır ve bu değerlerin aritmetik ortalaması kayacın Shore sertlik indeksini verir. Elde edilen değer aynı zamanda yüzeyin elastiklik özelliğinin de bir ölçüsüdür.

Birçok araștırmacı günümüze dek Shore sertlik indeksini çok çeşitli çalışmalarda kullanmışlardır. Szlavin [8] kayacın Shore sertlik indeksi ile diğer mekanik özellikleri arasında önemli ilișkiler bulmuş, ancak kayacın kazılabilirliği ve mekanik özellikleri arasında anlamlı ilişkiler elde edememiştir. Rabia ve Brook [9] Shore sertlik deneyinde numune yüksekliği, hacmi ve kenar etkisi gibi parametreleri araştırmıştır. Arthur [10] oldukça detaylı laboratuvar çalışmaları yürütmüş ve burada kayaçların sertliği, dayanımı ve aşındırcılığını birlikte değerlendirerek tünellerde kullanılan kazı sistemlerinin performans değerlendirmesini incelemiştir. Koncagül vd. [11] kayacın Shore sertlik ve bazı yapısal özelliklerinden yararlanarak tek eksenli basınç dayanımını elde etmeye çalışmıştır. Altındağ [12] kayaçların sıcaklığı arttıkça Shore sertliklerinin de arttığını ortaya koymuștur. Yașar ve Erdoğan [13] ile Shalabi vd. [14] kayaçların bazı sertlik indeks değerlerini kullanarak fizikomekanik ve diğer mühendislik özelliklerini tahmin etmeye çalışmıştır. Yurdakul ve Akdaş [15] doğal taşların fiziko-mekanik özellikleri ve Shore sertlik indeksinden yararlanarak yürüttükleri istatistiksel analizlerde, geniș çaplı dairesel testerelerin kesilmesi sırasında harcadıkları spesifik enerjiyi tahmin etmeye çalışmıştır. Sengun [16] karbonatlı kayaçların sıcaklığındaki değișimin kayacın fiziksel ve mekanik özellikleri üzerindeki etkisini incelemiștir. $\mathrm{Bu}$ bağlamda Shore sertliğinin özellikle $200^{\circ} \mathrm{C}$ üzerinde azaldığını belirlemiștir. Klawitter vd. [17] kömürün Shore sertliğinin kömürün litotipine bağlı olarak etkilendiğini ortaya koymuştur. Tumac ve Hojjati [18] darbeli kırıcıların performansının tahmin edilmesi için geliștirdiği modelde Shore sertlik indeksinden yararlanmıștır. Dogruoz vd. [19] bire bir ölçekli kesme setinde yürüttüğü kesme deneyleri sırasında harcanan spesifik enerji değerleri ile Shore sertlik indeksi arasındaki ilişkileri ortaya koymuştur.

\subsection{Equotip sertlik indeksi}

Equotip sertlik indeksi yaygın olarak metallerin yüzey sertliklerini test etmek üzere geliştirilmiştir. Portatif olarak 
taşınabilen, hem bilgisayar destekli hem de dahili hafızası ile çalıştırılabilen sertlik ölçerin üzerindeki LCD ekrandan sertlik değerleri okunmaktadır.

$3 \mathrm{~mm}$ çapa sahip küresel şekilli tungsten karbid bir uç kullanılarak ölçümler yapılmaktadır. Uçlar C, D, DC ve DL olarak sinıflandırılır. Deney aletinin ölçüm prensibi Leeb geri sekme yöntemini esas aldığı için okunan veriler Leeb sertlik değerleri olarak da ifade edilmektedir. Shore skeloroskobunda olduğu gibi bir yay mekanizması ile kayaç yüzeyine darbe uygulanır. Darbe öncesi ve sonrası kayaçta depolanan enerjiye bağlı olarak yayın geri sıçrama hızının ölçülmesine dayanmaktadır. Deney aletinin içyapısı Şekil 1'de gösterilmiştir [20].

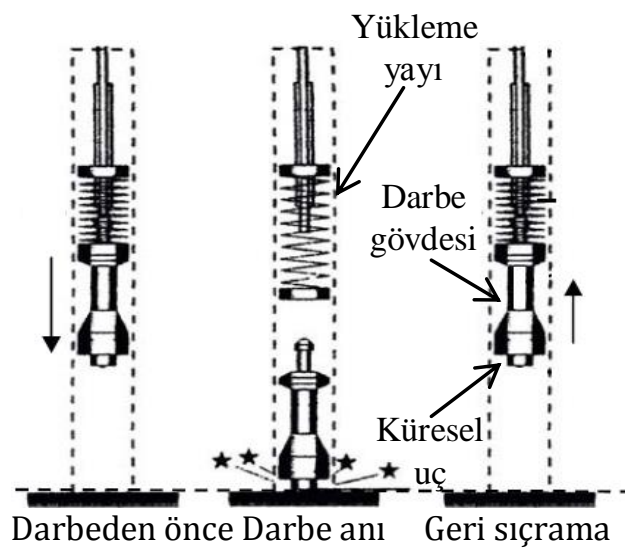

Şekil 1. Equotip sertlik ölçerin iç yapısı [20].

Deneyde kullanilacak numune yüzeylerinin pürüzsüz ve iyice parlatılmış olması gerekir. Deney yöntemi henüz kayaçlar için standart hale getirilmemiştir. Bu yüzden deneyde kullanılan belirli bir numune boyutu yoktur. Ancak uygulanan darbe şiddeti çok yüksek olmadığı için NX karot boyutlarında ve 25-30 mm kalınlığında örnekler üzerinde yürütülebilir. Her numune yüzeyinde en az 15 okuma yapılır ve aritmetik ortalaması Equotip sertlik değerini verir.
Sertlik ölçer aletin içerisindeki yay mekanizması vasıtasıyla $3 \mathrm{~mm}$ çapındaki tungsten karbür uç, kayaç yüzeyinde 0,011 Nm'lik darbe uygular. Yay vasitasıyla hareket ettirilen cismin darbe hızı $\left(V_{i}\right)$ ve geri sekme hızlarının $\left(V_{r}\right)$ karşılaştırılmasına göre sertlik değeri hesaplanır. $\mathrm{Bu}$ bağlamda Eşitlik 1'de verilen formülden sertlik değerleri "Leeb Hardness (HL)" okunur. Geri sekme hızı yumuşak numunelerde daha yavaş, sert numunelerde daha hızlıdır.

$$
H L=\frac{V_{r}}{V_{i}} \cdot 1000
$$

Burada; HL Equotip sertlik indeksi değeri, $V_{r}$ darbe sonrası geri sıçrama hızı, $V_{i}$ darbe hızıdır.

Equotip sertlik ölçer kullanılarak çeşitli araştırmacılar farklı çalışmalar yapmiștir. Verwaal ve Mulder [21] bu deney aletini kayaçlar üzerine uygulayan ilk araştırmacılardandır. Bu bağlamda kendileri kayacın basınç dayanımını laboratuvar ortaminda tahmin etmeye çalıșmışlardır. Meulenkamp ve Grima [22] Equotip sertliğini yapay sinir ağlarına uygulayarak kayacın basınç dayanımını tahmin etmeye çalışmıştır.

\section{Materyal ve Metot}

Kayaçların delinebilirlik, sertlik ve mekanik özelliklerini belirlemek üzere Zonguldak Taşkömürü Havzası'ndaki (ZTH) yeraltı galerileri ve karayolu tünellerinden blok örnekler alınmıştır. Bunun yanı sıra daha önce yurt dıșı araştırma çalışmaları sırasında Amerika'da Tucson (Arizona) şehrinde yapılan deneysel çalışmalardan da bazı örnekler kullanılmıştır. $\mathrm{Bu}$ örnekler Tucson'un 15 mil güneyindeki Mission bakır madeninden, 65 mil kuzeyinde bulunan Ray bakır madeninden ve $30 \mathrm{mil}$ batısındaki Coyote dağı eteklerinden alınmıştır. Örnekler alınırken anizotropi etkisini ortadan kaldırmak için çatlak ve süreksizlik içermemesine dikkat edilmiştir (Tablo 1). 
O. Su \& M. Momayez/ Kayaçların Equotip Sertlik İndeksi ile Mekanik Özellikleri ve Delinebilirliği Arasındaki İlişkiler

Tablo 1. Numunelerin alındığı yerler.

\begin{tabular}{clll}
\hline Kod & Kayaç Türü & Lokasyon & Ülke \\
\hline S1 & Kiltaşı & Kazpınarı madeni, Bartın & \\
S2 & Kumtaşı & Üzülmez karayolu tüneli, Zonguldak & \\
S3 & Kumtașı (İnce taneli) & TTK Karadon Müessesesi, Zonguldak & \\
S4 & Kireçtaşı (Killi) & Karayolu çalışması, Bartın & \\
S5 & Kireçtaşı & Mithatpaşa karayolu tüneli, Zonguldak & \\
S6 & Konglomera & TTK Kozlu Müessesesi, Zonguldak & Türkiye \\
S7 & Silttaşı & Balıkesir & \\
S8 & Kumtaşı & Balıkesir & \\
S9 & Mermer & Mermer ocağı, Eflani, Karabük & \\
S10 & Kireçtaşı & Karayolu çalışması, Zonguldak & \\
S11 & Silttaşı & Aslankaya karayolu tüneli, Zonguldak & \\
S12 & Bej mermer & Mermer ocağı, Çakraz, Bartın & \\
\hline S13 & Granit porfir & Mission madeni, Tucson & \\
S14 & Granit & Mission madeni, Tucson & Amerika \\
S15 & Tonalit & Coyote dağı, Tucson & \\
S16 & Granit & Coyote dağı, Tucson & \\
S17 & Milonit & Ray madeni, Tucson & \\
S18 & Granit & Ray madeni, Tucson & \\
S19 & Granodiyorit & Ray madeni, Tucson & \\
\hline
\end{tabular}

Araziden alınan blok numunelerin mekanik özellikleri belirlenmiş, delinebilirlik ve sertlik özellikleri incelenmiştir. Daha sonra henüz madencilik sektöründe uygulaması çok yaygınlaşmamış olan Equotip sertliğinin kayacın mekanik ve delinebilirlik özellikleri ile olan ilișkileri istatistiksel açıdan araştırılmıştır.

\subsection{Mekanik özelliklerin belirlenmesi}

Türkiye'de ve Amerika'da yapılan laboratuvar çalıșmaları kapsamında tüm örneklerin tek eksenli basınç ve dolaylı çekme dayanımı deneyleri yapılmış ve ayrıca Young modülleri belirlenmiştir. $\mathrm{Bu}$ amaçla $54 \mathrm{~mm}$ çapında ve $108 \mathrm{~mm}$ boyunda ve ayrıca $54 \mathrm{~mm}$ çapında ve 27 mm kalınlıkta silindirik örnekler ISRM standartlarına göre hazırlanmıştır (Şekil 2-3). Kayaçların mekanik özellikleri belirlendikten sonra Altındağ $[23,24]$ tarafından önerilen Eșitlik 2'deki ampirik bağıntıdan yararlanılarak kırılganlık değerleri hesaplanmıştır.

$$
B=\frac{\sigma_{C} \cdot \sigma_{t}}{2}
$$

Burada; B kırılganlık, $\sigma_{\mathrm{c}}$ tek eksenli basınç (MPa), $\sigma_{t}$ dolaylı çekme dayanımıdır (MPa).

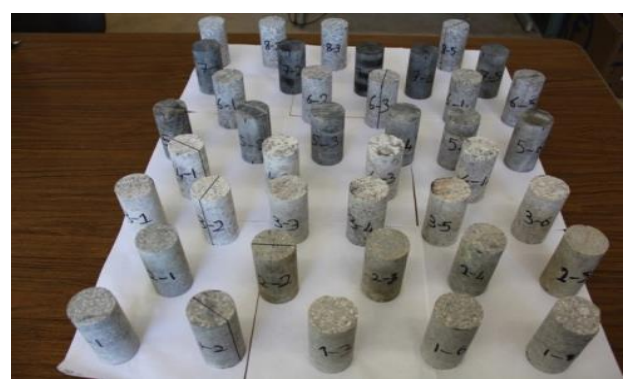

Şekil 2. Tek eksenli basınç dayanımı ve deformasyon deney örnekleri

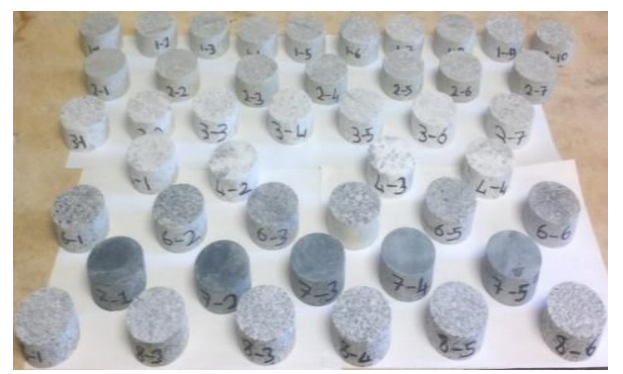

Şekil 3. Brazilian dolaylı çekme dayanımı deneyi için hazırlanan örnekler

\subsection{Delme oranı indeksinin belirlenmesi}

Kayaçların delinebilirliklerinin önceden tahmininde kullanılan delme oranı indeksi (DRI) deneyi araziden alınan örneklere uygulanmıştır. 
O. Su \& M. Momayez/ Kayaçların Equotip Sertlik İndeksi ile Mekanik Özellikleri ve Delinebilirliği Arasındaki İlişkiler

Deney yöntemine göre kayacın karbür uç ile numunenin beş farklı kırılganlık değeri $\left(S_{20}\right)$ ve Sievers noktasında $1 \mathrm{dk}$ 'lk delme sürelerinde minyatür delme deney (SJ) ucun batma derinliği ölçülmüştür. Elde sonuçlarından elde edilen DRI verileri edilen değerler kayacın Sievers minyatür birlikte değerlendirilerek çeşitli kazı delme değeri (SJ) olarak kayıt edilmiştir. makinalarının (jumbo delici, galeri açma Kırılganlı ve SJ delme deneyleri makinesi, tünel açma makinası, vb.) Zonguldak Taşkömürü Havzası'ndan performans tahmini ve maliyet analizleri alınan numuneler üzerinde yapılmıș ve yapılır [25]. Çünkü deliklerin delinmesi her kayaç türü için üç kere tekrarlanarak patlatma maliyetinin en önemli kısmıdır.

Çizelge 1'de sunulan sahalardan alınan numuneler laboratuvara getirildikten sonra kırılganlı deneyi $\left(\mathrm{S}_{20}\right)$ için -16 $\mathrm{mm} /+11,2 \mathrm{~mm}$ elek aralı̆̆ında yaklaşık 500 gr'lı numuneler hazırlanmıștır. Deney yöntemine göre 14 kg ağırlı̆̆ındaki çekiç, $25 \mathrm{~cm}$ yükseklikten 20 defa numune üzerine düşürüldükten sonra 11,2 mm'lik elekten elenmiştir. Elek altına geçen malzeme miktarının, deney başlangıcında tartılan malzeme miktarına ağırlığına oranından numunenin kırılganlık değeri hesaplanmıștir [26]. Ayrıca, NX boyutlarında ve $27 \mathrm{~mm}$ kalınlığında ince karot örnekleri hazırlanmıștır. Daha sonra $110^{\circ}$ tepe açısına sahip tungsten

\subsection{Shore ve Equotip sertlik indekslerinin belirlenmesi}

Kayaçların delinebilirlik özelliklerinin belirlenmesinin yanı sıra laboratuvarda kayaçların sertlik indeks değerleri de belirlenmiștir. Her iki deney aletinin çalışma prensibinin birbirine oldukça benzerdir. $\mathrm{Bu}$ bağlamda hem Türkiye ve hem de Amerika'dan alınan örneklerin Shore ve Equotip sertlikleri belirlenmiștir. Deneyler her kayaç birimi için üç defa tekrarlanmıș ve ortalamaları alınmıştır. Deneysel çalışmalarda kullanılan D model Shore skeloroskobu ve Equotip sertlik ölçer Șekil 4'de gösterilmiştir.
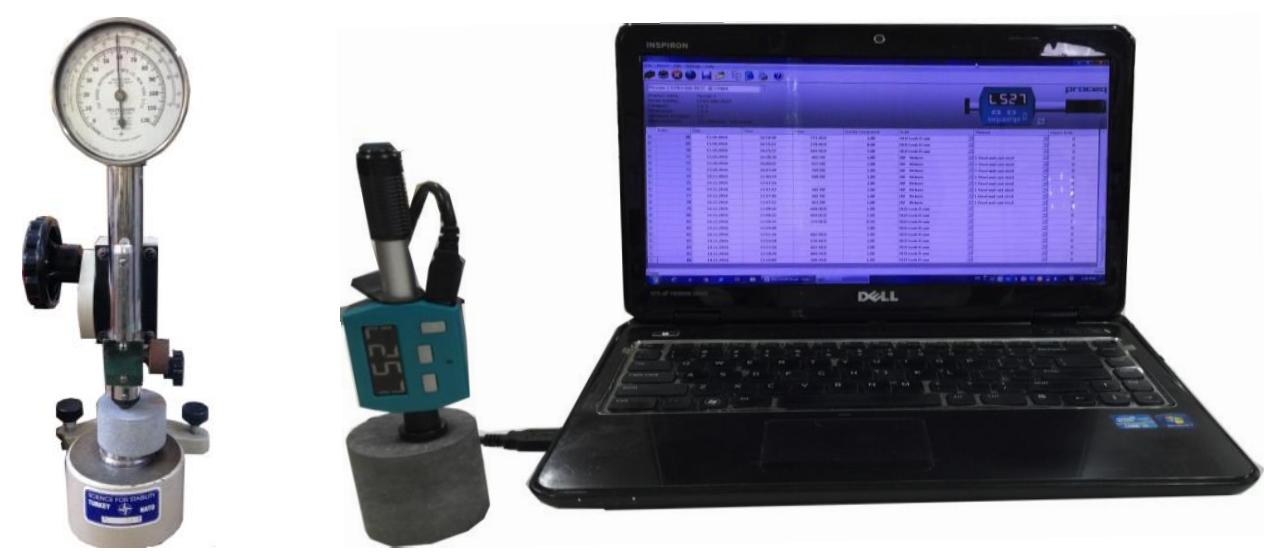

Şekil 4. Shore skeloroskobu ve Equotip sertlik ölçerin genel görünümü

\section{Bulgular}

Arazide delme ve ilerleme hızlarının belirlenmesi ve makina performansının tahmin edilmesi için delinebilirliğe etki eden parametrelerin iyi bir şekilde irdelenmesi gerekmektedir. Bu çalıșmada da yurt içi ve yurt dişından alınan örneklerin mekanik, delinebilirlik ve sertlik indeksleri belirlenmiștir. $\mathrm{Bu}$ bağlamda elde edilen sonuçlar Tablo 2'de sunulmuștur. 
O. Su \& M. Momayez/ Kayaçların Equotip Sertlik İndeksi ile Mekanik Özellikleri ve Delinebilirliği Arasındaki İlişkiler

Tablo 2. Deneysel çalıșmaların sonuçları.

\begin{tabular}{ccccccccccc}
\hline Kod & $\gamma$ & $\sigma_{\mathrm{C}}$ & $\sigma_{\mathrm{t}}$ & $\mathrm{E}$ & $\mathrm{S}_{20}$ & $\mathrm{SJ}$ & $\mathrm{DRI}$ & $\mathrm{B}$ & $\mathrm{HL}$ & $\mathrm{SH}$ \\
\hline S1 & 2.62 & 25,0 & 4,0 & - & 51 & 84 & 64 & 50 & 449 & 18.6 \\
S2 & 2.63 & 75,0 & 18,3 & - & 30 & 94 & 43 & 685 & 612 & 40.4 \\
S3 & 2.61 & 71,0 & 12,8 & 18.9 & 38 & 78 & 48 & 455 & 595 & 31.3 \\
S4 & 2.66 & 43,0 & 12,0 & - & 39 & 64 & 48 & 258 & 686 & 36.2 \\
S5 & 2.67 & 56,0 & 8,8 & 7.5 & 52 & 92 & 64 & 246 & 525 & 31.9 \\
S6 & 2.48 & 44,0 & 7,0 & - & 52 & 58 & 53 & 130 & 610 & 32.1 \\
S7 & 2.37 & 81,0 & 11,8 & 14.8 & 35 & 80 & 47 & 478 & 577 & 30.8 \\
S8 & 2.43 & 57,5 & 8,4 & 8.5 & 42 & 92 & 54 & 242 & 645 & 41.2 \\
S9 & 2.65 & 68,4 & 8,7 & 24.4 & 46 & 62 & 55 & 297 & 635 & 44.3 \\
S10 & 2.63 & 70,0 & 7,2 & 22.9 & 44 & 58 & 53 & 252 & 630 & 35.1 \\
S11 & 2.62 & 47,0 & 5,1 & - & 65 & 99 & 69 & 94 & 506 & 26.3 \\
S12 & 2.68 & 71,0 & 12,0 & 21.5 & 41 & 55 & 51 & 426 & 650 & 34.2 \\
S13 & 2.56 & 112,3 & 15,3 & 59.6 & - & - & - & 859 & 925 & - \\
S14 & 2.53 & 98,0 & 10,8 & 48.4 & - & - & - & 527 & 891 & - \\
S15 & 2.56 & 134,9 & 7,1 & 38.3 & - & - & - & 481 & 817 & - \\
S16 & 2.44 & 117,8 & 8,6 & 46.2 & - & - & - & 505 & 858 & - \\
S17 & 2.63 & 125,7 & 13,5 & 73.9 & - & - & - & 846 & 870 & - \\
S18 & 2.52 & 91,8 & 11,5 & 54.9 & - & - & - & 527 & 850 & - \\
S19 & 2.59 & 93,0 & 7,5 & 21.2 & - & - & - & 350 & 834 & - \\
\hline
\end{tabular}

Burada; $\gamma$ kayacın yoğunluğu (gr/ $\left.\mathrm{cm}^{3}\right)$, $\sigma_{\mathrm{c}}$ kayacın tek eksenli basınç dayanımı (MPa), $\sigma_{\mathrm{t}}$ kayacın dolaylı çekme dayanımı (MPa), E Young modülü (MPa), S20 kırllganlığı, SJ Sievers minyatür delme değeri, DRI delme oranı indeksi, HL Equotip sertlik değeri, SH Shore sertlik indeksidir.

Çizelge 2'de verilen sonuçlar derlenerek istatistiksel analizler yapılmıștır. Buna göre öncelikli olarak Shore sertlik indeksi ile Equotip sertlik indeksi arasındaki ilişki incelenmiştir. $\mathrm{Bu}$ bağlamda yurt içinden alınan örneklerin Shore değerleri ile Equotip sertlik değerleri arasında Şekil 5'de sunulan lineer bir ilişki olduğu tespit edilmiştir.
Equotip sertliğinde kullanılan ucun çapının küçük olması ve kayac yüzeyindeki minerallerin sertlikleri arasında farklılık olması sonuçları oldukça etkilemektedir. $\mathrm{Bu}$ nedenle Equotip sertliği ölçülürken kayacın içerisindeki mineral dağılımlarının net olarak incelenmesi ve ölçümlerin hassas bir şekilde yapılması gerekmektedir.

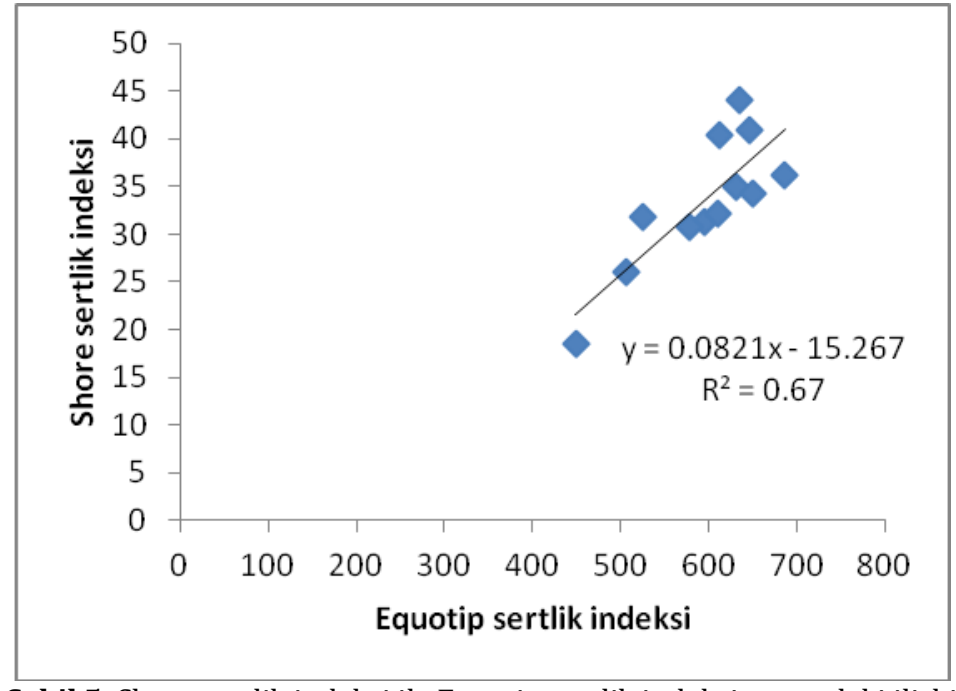

Şekil 5. Shore sertlik indeksi ile Equotip sertlik indeksi arasındaki ilişki 
Shore sertlik indeksi ile kayacın dayanım özellikleri hızlı bir şekilde tahmin edilebilmektedir. Bu bağlamda Equotip sertliği ile benzer bir tahmin yapılıp yapılmayacağı araştırılmıştır. Buna göre yapılan deneysel çalışmalar sonucunda kayacın tek eksenli basınç dayanımı ile Equotip sertlik indeksi arasında lineer bir ilişski olduğu tespit edilmiștir (Şekil
6). Yani, kayaçların basınç dayanımı arttıkça Equotip sertlik indeksi de artmaktadır. Ancak, Equotip sertlik deneyinde ucun geri sıçrama hızı yumuşak kayaçlarda yanıltıcı sonuçlar verebilmektedir. $\mathrm{Bu}$ nedenle Equotip sertliği 400 veya dayanımı 19 MPa'dan büyük olan kayaçlarda daha gerçeğe yakın sonuçlar elde edilecektir.

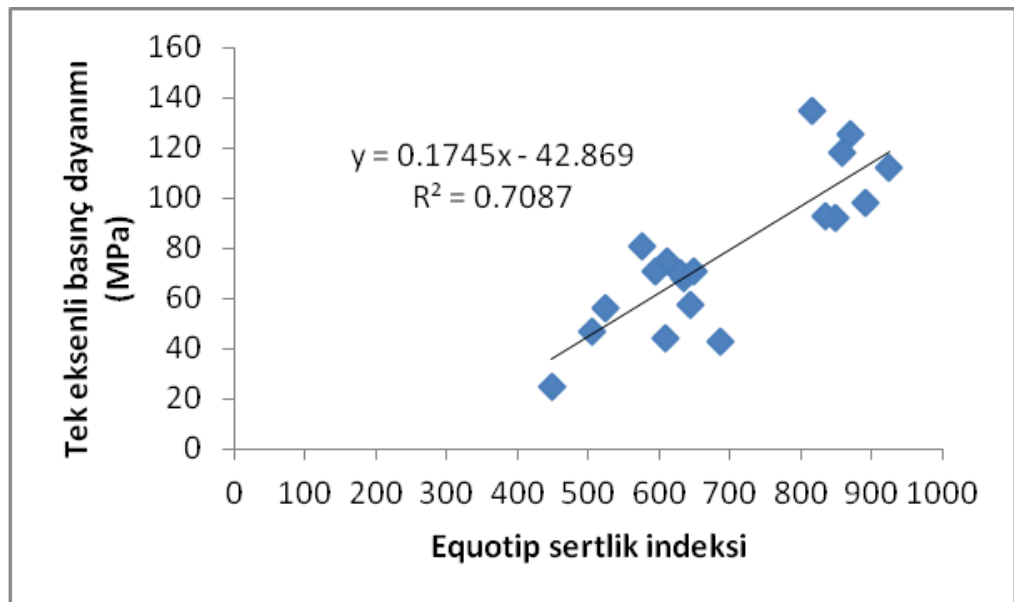

Şekil 6. Tek eksenli basınç dayanımı ile Equotip sertlik indeksi arasındaki ilişki

Kayaçların mekanik özelliklerini gösteren en önemli parametrelerden bir tanesi de Young modülüdür. Kayaçların sertlikleri, yapisında bulunan minerallerin elastiklik özelliklerini yansıtmaktadır. $\mathrm{Bu}$ bağlamda araziden alınan blok örneklerin bazılarından 110 mm'den daha uzun silindirik numuneler hazırlanmış ve bu numunelerin tek eksenli basınç dayanımı deneyi sonrası çizilen eksenel gerilme - eksenel deformasyon grafiklerinin eğiminden Young modülleri hesaplanmıștır. Buna göre kayacın Young modülü ile Equotip sertliği arasında korelasyon katsayısı 0,86 olan doğrusal bir ilișki olduğu belirlenmiștir (Şekil 7). Dolayısı ile kayacın yüzey sertliğinin kayacın elastik özelliği ile yakından iliş̧ili olduğu tespit edilmiştir. Şekil 6-7'deki sonuçlar irdelendiğinde Equotip sertliği ile kayacın basınç dayanımı ve delinebilirlik özellikleri arasında Tablo 3'te verildiği gibi bir sınıflama elde edilmiştir. Ancak veri sayısı arttırılarak çizelgede verilen aralıkların hassasiyetleri teyit edilmelidir.

Tablo 3. Kayaçların delinebilirlik-sertlik sınıflaması.

\begin{tabular}{lcccl}
\hline Sertlik & $\sigma_{c}$ & HL & DRI & Delinebilirlik \\
\hline Çok yumuşak & $<19$ & $<399^{*}$ & $>70$ & Çok kolay \\
Yumuşak & $20-49$ & $400-549$ & $53-69$ & Orta derecede kolay \\
Sert & $50-69$ & $550-649$ & $43-52$ & Zor \\
Orta sert & $70-100$ & $650-799$ & $26-42$ & Orta derecede zor \\
Çok sert & $>100$ & $>800$ & $<25$ & Çok zor \\
\hline
\end{tabular}

* Dikkate alınmaması önerilir.

$\sigma_{c}$ tek eksenli basınç dayanımı(MPa), HL Equotip sertlik indeksi, DRI delme oranı indeksidir. 
O. Su \& M. Momayez/ Kayaçların Equotip Sertlik İndeksi ile Mekanik Özellikleri ve Delinebilirliği Arasındaki İlișkiler

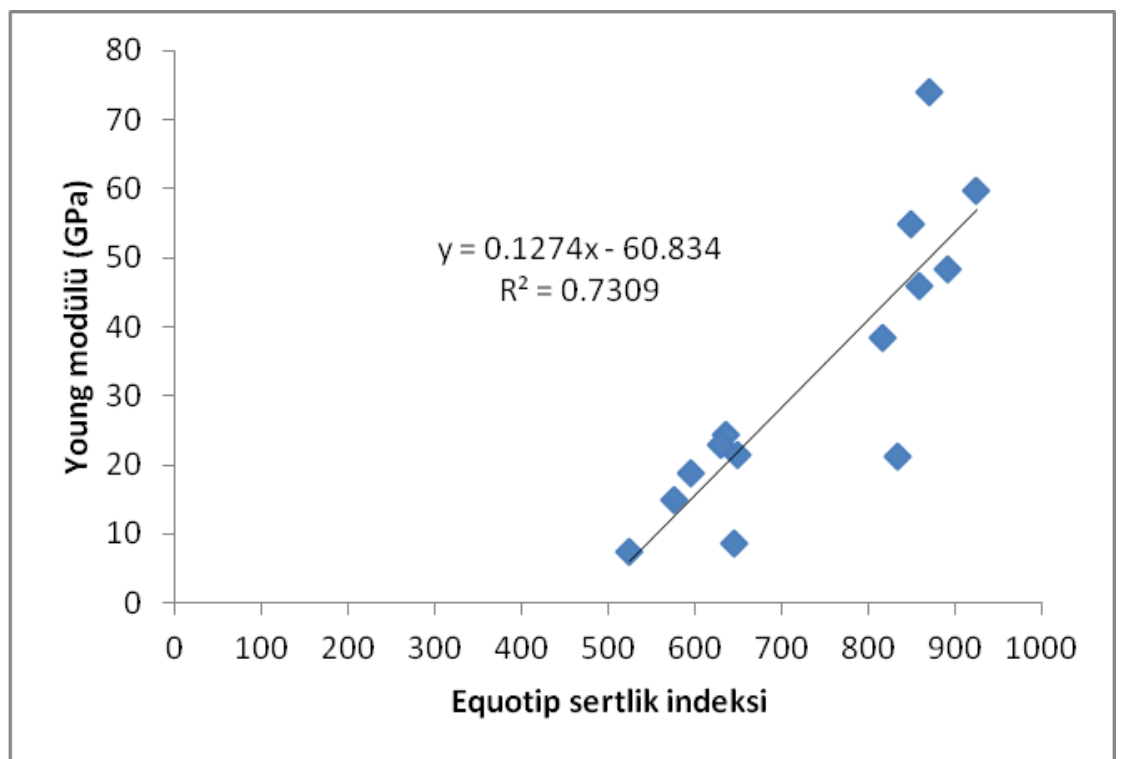

Şekil 7. Young modülü ile Equotip sertlik indeksi arasındaki ilişki

Diğer taraftan kayacın basınç ve çekme

Equotip sertlik indeksi arasındaki Şekil 8' dayanımının bir ölçütü olarak Eşitlik 2'de de verildiği gibi üstel bir ilişkinin olduğu verilen ampirik bağıntıdan kırılganlık ve görülmüştür.

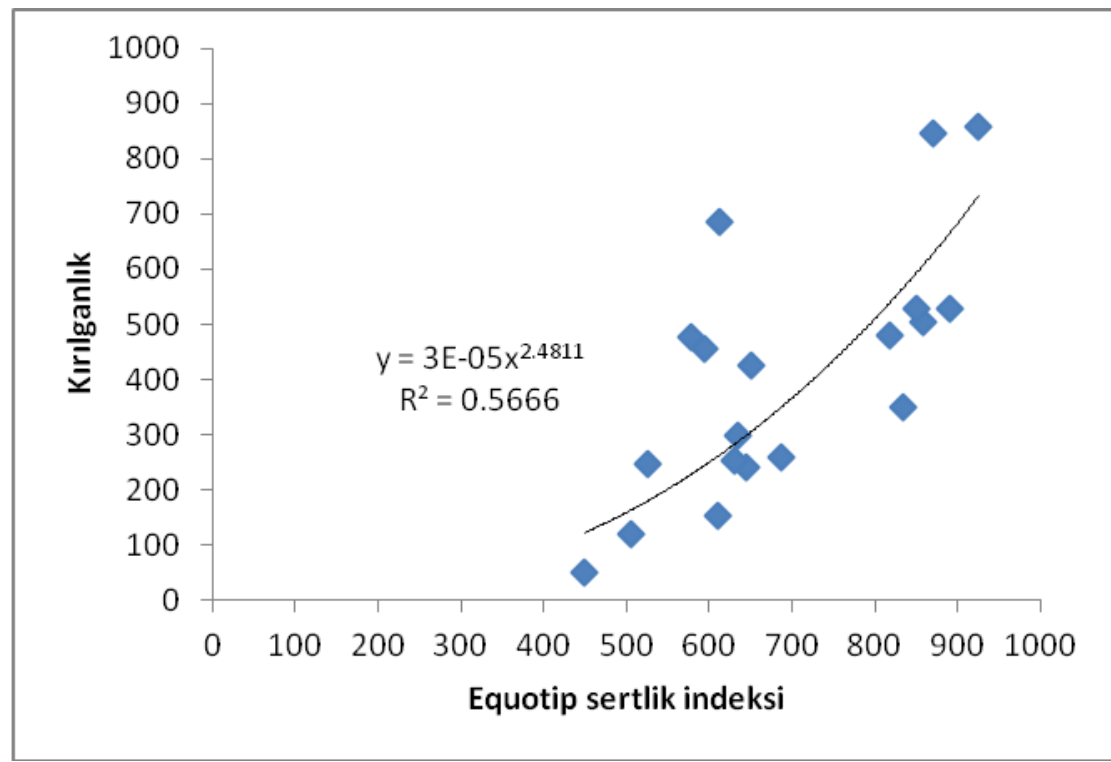

Şekil 8. Kırılganlık ile Equotip sertlik indeksi arasındaki ilişki

Laboratuvarda yürütülen deneysel doğrusal bir değişimin olduğu çalışmaların sonucunda yurt içinden bulunmuştur. Buna göre Equotip sertlik alınan örneklerin delme oranı indeksi ve Equotip sertlikleri arasındaki ilişki değeri düşük olan kayaçların daha kolay istatistiksel açıdan değerlendirildiğinde delinebilir olduğu belirlenmiştir. Şekil 9'da sunulduğu gibi negatif yönlü göre delme oranı indeks değeri 70'den 
O. Su \& M. Momayez/ Kayaçların Equotip Sertlik İndeksi ile Mekanik Özellikleri ve Delinebilirliği Arasındaki İlişkiler

büyük olan kayaçların oldukça kolay hatalı sonuçlar gözlemlenebilecektir. Bu delinebilir olduğu bilinmektedir. Bu nedenle DRI değeri 70 'den büyük kayaçların dayanım değerleri düşük kayaçlarda Equotip sertlik değerinin olduğu için Equotip sertlik indeksinde uygulanabilirliği azalmaktadır.

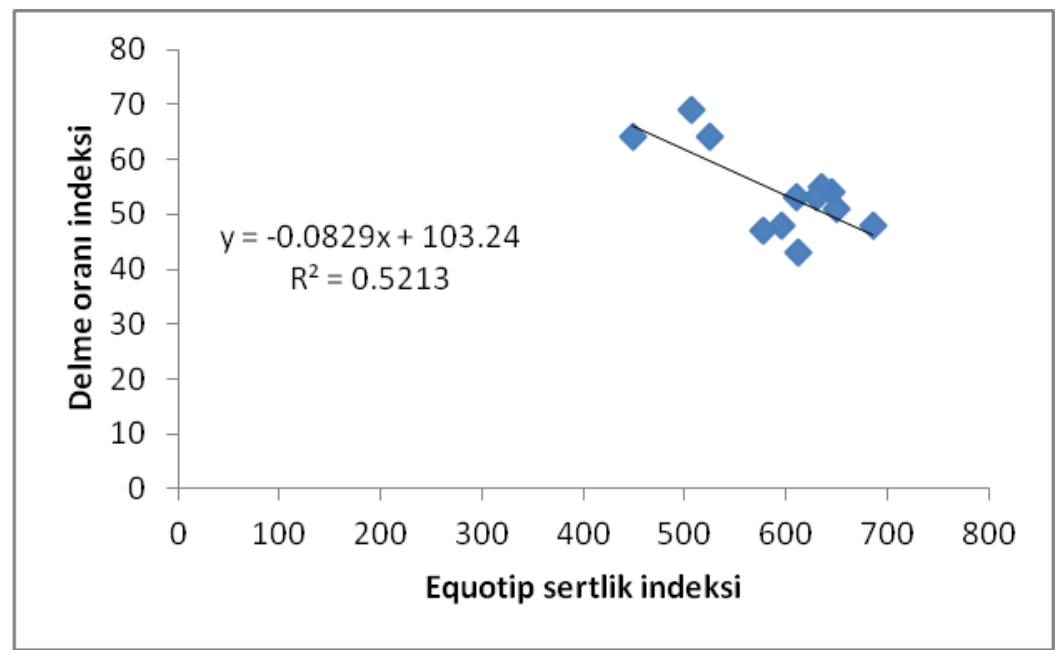

Şekil 9. Delme oranı indeksi ile Equotip sertlik indeksi arasındaki ilişki

\section{Tartışma ve Sonuç}

Gerek kazı mekaniği ve gerekse de kaya mekaniği deneylerinde bazen kayaçların mekanik, elastiklik ve delinebilirlik özelliklerini hızlı ve basit bir deney yöntemiyle tahmin etmek önemli bir kolaylık sağlamaktadır. Bu nedenle bu çalışmada Equotip sertlik deneyinin kayaçlarda incelenmiștir. uygulanabilirliğ

Yurt içi ve yurt dıșından alınan örnekler üzerinde yürütülen deneysel çalıșmalardan elde edilen sonuçlar ışığında Equotip sertlik deneyinin kayaçların yukarıda belirtilen özelliklerinin önceden tahmin edilmesinde uygulanabilir olduğu ortaya konmuștur. Yaplan basit regresyon analizlerinde elde edilen yüksek korelasyon katsayıları Equotip sertliği ile diğer kayaç özelliklerinin yakından ilişkili olduğu tespit edilmiștir. Ancak kayacın elastiklik özelliğinin düşük olduğu hallerde uç tarafindan harcanan darbe enerjisinin büyük bir kısmı kayaç yüzeyinde absorbe edilmekte ve bu nedenle ucun geri sıçrama hızında yavaşlama olmaktadır. Dolayısı ile deney yöntemi yumușak kayaçlarda hatalı sonuçlar verebilmektedir. $\mathrm{Bu}$ nedenle Equotip sertlik deneyinin basınç dayanımı 19 MPa'ın altında olduğu ve delme oranı indeksi değerinin 70 'den büyük olduğu kayaçlarda uygulanmasının oldukça sınırlı olduğu dikkate alınmalıdır.

Literatürde yapılan çalıșmalar incelendiğinde daha çok Schmidt çekici ile Equotip sertlik indeksi ilişskilendirilmiştir. Aoki ve Matsukura [28] kumtașı bloklarındaki ince așınmıș katmanların dayanımını değerlendirmek üzere Schmidt ve Equotip sertlik ölçerle arazide ölçümler yapmış ve Equotip sertliğinin Schmidt'ten daha güvenilir olduğunu ileri sürmüştür. Bu çalışmada ise Shore sertlik indeksi ile Equotip sertlik indeksi karşılaștırılmıș ve korelasyon katsayısı 0,82 olduğu belirlenmiștir.

Diğer taraftan Kawasaki vd. [29] karot örnekleri üzerinde Equotip sertlik, basınç 
O. Su \& M. Momayez/ Kayaçların Equotip Sertlik İndeksi ile Mekanik Özellikleri ve Delinebilirliği Arasındaki İlișkiler

dayanımı ve elastik dalga deneyleri yapmıştır. Ancak yapılan çalışmalar sonucunda Equotip sertliği ile kayacın tek eksenli basınç dayanımı arasında korelasyon katsayısının düşük olduğu ilişkiler bulmuşlardır. Bu çalışmada ise korelasyon katsayısı 0,86 çıkmıştır. Hack ve Huisman [30] ise kayacın yerinde dayanımını tahmin etmek üzere Equotip sertlik ölçer kullanmış ve bu anlamda "basit ortalamalar" yöntemi kullanarak sonuçların yorumlanmasının daha anlamlı olacağını vurgulamışlardır.

Diğer taraftan çalışmada elde edilen özgün sonuçlardan bazıları kayaçların kırılganlık özelliği ve delme oranı indeksinin Equotip sertlik indeksi ile olan ilişkileridir. Sertlik indeksleri ve kırılganlı delinebilirliğin önceden tahmin edilmesinde oldukça sağlıklı sonuçlar vermektedir. $\mathrm{Bu}$ durum bu çalışmada da ortaya çıkmış ve delme oranı indeksi ile Equotip sertlik indeksi arasında korelasyon katsayısı 0,72 olan negatif yönlü doğrusal bir ilișki bulunmuştur. Literatürde yapılmıș benzer bir çalışma henüz bulunmamaktadır.

Yukarıda verilen korelasyon katsayıları her ne kadar yüksek olsa da deney yapılan kayaç sayısı sınırlıdır. Bu nedenle verilen ilişkilerdeki korelasyon katsayılarının daha fazla kayaç üzerinde $\mathrm{t}$ ve $\mathrm{F}$ testleri ile desteklenen regresyon modelleri ile sonuçlarının güvenilirliğinin arttırılması anlamlı olacaktır.

\section{Teșekkür}

Yazar, bu çalışmayı destekleyen Bilimsel Araștırma Projeleri Koordinatörlügüne (Proje No: 2014-29011448-02), YÖK Doktora Sonrası Araştırma Destek Programina ve delme oranı indeksi deneylerinde yardımlarını esirgemeyen Arş. Gör. Utku Sakız'a (BEÜ) teşekkürlerini sunar.
Kaynakça

[1] Altindag, R., Guney, A. 2005. Effect of the Specimen Size on the Determination of Consistent Shore Hardness Values, International Journal of Rock Mechanics and Mining Sciences, Cilt. 42, No. 1, s.153-160. DOI:10.1016/j.ijrmms 2004.08.002

[2] ISRM. 1978. Suggested Methods for Determining Hardness and Abrasiveness of rocks, International Journal of Rock Mechanics and Mining Sciences \& Geomechanics Abstracts, Cilt. 15, No. 3, s. 89-97. DOI: $10.1016 / 0148-9062(78) 90002$ $-5$

[3] Su, O. 2003. Kömürün Dayanım Özellikleri ile Ögütülebilirliği Arasındaki İlişkilerin Araştırılması. Y. Lisans Tezi, Zonguldak Karaelmas Üniversitesi, Fen Bilimleri Enstitüsü, 100s, Zonguldak.

[4] Holmgeirsdottir, T., Thomas, PR. 1998. Use of the D-762 Shore Hardness Scleroscope for Testing Small Rock Volumes, International Journal of Rock Mechanics and Mining Sciences, Cilt. 35, s. 85-92. DOI:10.1016/S0148-9062(97)0031 7-3

[5] ASTM E448-82. 2012. Standard Practice for Scleroscope Hardness Testing of Metallic Materials, $5 \mathrm{~s}$.

[6] Altindag, R., Guney, A. 2006. ISRM Suggested Method for Determining the Shore Hardness Value for Rock, International Journal of Rock Mechanics and Mining Sciences, Cilt. 43, s. $19-22$. DOI: $10.1016 /$ j.ijrmms. 2005.04.004

[7] ASTM D5873-05. 2012. Standard Test Method for Determination of Rock Hardness by Rebound Hammer Method, 4 s.

[8] Szlavin, J. 1974. Relationships between Some Physical Properties of Rock Determined by Laboratory Tests, International Journal of Rock Mechanics and Mining Sciences \& 
O. Su \& M. Momayez/ Kayaçların Equotip Sertlik İndeksi ile Mekanik Özellikleri ve Delinebilirliği Arasındaki İlişkiler

Geomechanics Abstracts, Cilt. 12, No. 2, s.57-66. DOI: 10.1016/01489062(74)92649-7

[9] Rabia, H., Brook, N. 1979. Shore Hardness of Rock, International Journal of Rock Mechanics and Mining Sciences \& Geomechanics Abstracts, Cilt. 16, s.335-336. DOI:10.1016/0148-9062(79)90245 $-6$

[10] Arthur, C.D. 1996. The Determination of Rock Material Properties to Predict the Performance of Machine Excavation in Tunnels, Quarterly Journal of Engineering Geology, Cilt. 29, s. 6781.DOI:10.1144/GSL.QJEGH.1996.0 29.P1.05

[11] Koncagül, E.C., Santi, P.M. 1999. Predicting the Unconfined Compressive Strength of the Breathitt Shale Using Slake Durability, Shore Hardness and Rock Structural Properties, International Journal of Rock Mechanics and Mining Sciences, Cilt. 36, No. 2, s.139-153.DOI:10.1016/ S01489062(98)00174-0

[12] Altindag, R. 2002. Effects of Specimen Volume and Temperature on Measurements of Shore Hardness, Rock Mechanics and Rock Engineering, Cilt. 35, No. 2, s.109113. DOI: $10.1007 /$ s006030200014

[13] Yaşar, E., Erdoğan, Y. 2004. Estimation of Rock Physicomechanical Properties Using Hardness Methods, Engineering Geology, Cilt. 71, No. (3-4), s. 281288. DOI:10.1016/S0013-7952(03) 00141-8

[14] Shalabi, F.I., Cording, E.J., AlHattamleh, O.H. 2007. Estimation of rock Engineering Properties Using Hardness Tests, Engineering Geology, Cilt. 90, No. 3-4, s. 138-147. DOI: 10.1016/j.enggeo. 2006.12.006

[15] Yurdakul, M., Akdaș, H. 2012. Prediction of Specific Cutting Energy for Large Diameter Circular
Saws During Natural Stone Cutting, International Journal of Rock Mechanics and Mining Sciences, Cilt. 53, s. 38-44. DOI: 10.1016/j.ijrmms. 2012.03.008

[16] Sengun, N. 2014. Influence of Thermal Damage on the Physical and Mechanical Properties of Carbonate Rocks, Arabian Journal of Geoscience, Cilt. 7, s. 5543-5551. DOI: $10.1007 / s 12517-013-1177-x$

[17] Klawitter, M., Joan, E., Sarah, C. 2015. A Study of Hardness and Fracture Propagation in Coal, International Journal of Rock Mechanics and Mining Sciences, Cilt. 76 , s. 236-242. DOI:10.1016/ j.ijrmms. 2015.02.006

[18] Tumac, D., Hojjati, S. 2016. Predicting Performance of Impact Hammers from Rock Quality Designation and Compressive Strength Properties in Various Rock Masses, Tunnelling and Underground Space Technology, Cilt. 59, s. 38-47. DOI: 10.1016/ j.tust.2016.06.008

[19] Dogruoz, C., Bolukbasi, N., Rostami, J. 2016. An Experimental Study of Cutting Performances of Worn Picks, Rock Mechanics and Rock Engineering, Cilt. 49, No. 1, s. 213224.DOI:10.1007/s00603-015-0734 $-\mathrm{x}$

[20] Aoki, H., Matsukura, Y. 2007. Estimating the unconfined compressive strength of intact rocks from Equotip hardness. Bulletin of Engineering Geology and Environment, Cilt. 67, s.23-29. DOI: 10.1007/s10064-007-0116-z

[21] Verwaal, W., Mulder, A. 1993. Estimating Rock Strength with the Equotip hardness tester, International Journal of Rock Mechanics and Mining Sciences \& Geomechanics Abstracts, Cilt. 30, No. 6, S. 659-662. DOI: 10.1016/0148-9062(93)91226-9 
O. Su \& M. Momayez/ Kayaçların Equotip Sertlik İndeksi ile Mekanik Özellikleri ve Delinebilirliği Arasındaki İlişkiler

[22] Meulenkamp, F., Grima, M.A. 1999. Application of Neural Networks for the Prediction of the Unconfined Compressive Strength (UCS) from Equotip Hardness. International Journal of Rock Mechanics and Mining Sciences, Cilt. 36, No. 1, s. 2939. DOI: $10.1016 / \mathrm{S} 0148-9062(98)$ 00173-9

[23] Altindag, R. 2002. The Evaluation of Rock Brittleness Concept on Rotary Blast Hole Drills, Journal of The South African Institute of Mining and Metallurgy, Cilt. 102, No. 1, s. 61-66.

[24] Altindag, R. 2003. Correlation of Specific Energy with Rock Brittleness Concepts on Rock Cutting, Journal of The South African Institute of Mining and Metallurgy, Cilt. 103, No. 3, s.163172.

[25] Dahl, F., Grøv, E., Breivik, T. 2007. Development of a New Direct Test Method for Estimating Cutter Life, Based on the Sievers' J Miniature Drill Test, Tunnelling and Underground Space Technology, Cilt. 22, No. 1, s. 106-116. DOI: 10.1016/j.tust.2006.03.001

[26] Blindheim, O.T., Bruland, A. 1998. Boreability testing. Norwegian TBM Tunnelling 30 Years of Experience with TBMs in Norwegian Tunnelling, s. 29-34, Oslo, Norway.

[27] Dahl, F. 2003. DRI, BWI, CLI Standard. SINTEF report, Norway, $21 \mathrm{~s}$.

[28] Aoki, H., Matsukura, Y. 2007. A New Technique for Non-destructive Field Measurement of Rock-surface Strength: An Application of the Equotip Hardness Tester to Weathering Studies. Earth Surface Processes and Landforms, Cilt. 32, s.1759-1769.DOI:10.1002/esp.1492

[29] Kawasaki, S., Tanimoto, C., Koizumi, K., Ishikawa, M. 2002. An Attempt to Estimate Mechanical Properties of Rocks Using the Equotip Hardness
Tester, Jouornal of Japan Society Engineering Geology, Cilt. 43, No. 4, s.244-248.DOI:10.5110/jjseg.43.244

[30] Hack, H.R., Huisman, M. 2002. Estimating the Intact Rock Strength of a Rock Mass by Simple Means, 9th Conference of the International Association for Engineering Geology and the Environment, s. 1671-1677, Durban, South Africa. 